\title{
Modelling of the gas-phase phosphate group loss and rearrangement in phosphorylated peptides
}

\author{
Marko Rožman
}

The gas-phase dissociation of phosphorylated peptides was modelled using a combination of quantum mechanics and the Rice-Ramsperger-Kassel-Marcus theory. Potential energy surfaces and unimolecular reaction rates for several low-energy fragmentation and rearrangement pathways were estimated, and a general mechanism was proposed. The neutral loss of the phosphoric acid was mainly an outcome of the intramolecular nucleophilic substitution mechanism. The mechanism involves a nucleophilic attack of the phosphorylated amino acid N-terminal carbonyl oxygen on b-carbon, yielding a cyclic ve-membered oxazoline product ion. Regardless of the proton mobility, the pathway was charge directed either by a mobile proton or by a positively charged side chain of some basic residue. Although the mechanistic aspects of the phosphate loss are not in uenced by the proton mobility environment, it does affect ion abundances. Results suggest that under the mobile pro-ton environment, the interplay between phosphoric acid neutral loss product ion and backbone cleavage fragments should occur. On the other hand, when proton mobility is limited, neutral loss product ion may predominate. The frag-mentation dynamics of phosphoserine versus phosphothreonine containing peptides suggests that $\mathrm{H}_{3} \mathrm{PO}_{4}$ neutral loss from phosphothreonine containing peptides is less abundant than that from their phosphoserine containing analogs. During the low-energy CID of phosphorylated peptides in the millisecond time range, typical for ion trap instruments, a phos-phate group rearrangement may happen, resulting in an interchange between the phosphorylated and the hydroxylated residues. Unimolecular dissociation rate constants imply the low abundance of such scrambled product ions.

Keywords: molecular modelling; fragmentation mechanisms; collision induced dissociation; phosphorylation; reaction mechanisms

\section{INTRODUCTION}

Mass spectrometry methods have become preferred for phosphoprotein or phosphopeptide classification (identification, characterisation and quantification) ${ }^{[1,2]}$. To date, most MS-based approaches dealt with phosphorylation at the peptide level. In a typical scenario, enriched phosphopeptides are ionised by electrospray ionisation or matrix-assisted laser desorption ionisation and subsequently analysed by examining a measured mass and a collision-induced dissociation (CID) ${ }^{[3-9]}$ spectra. The presence of phosphorylated serine (pSer), threonine (pThr) or tyrosine residue has been mainly identified by observing the elimination of phosphoric acid $\left(\mathrm{H}_{3} \mathrm{PO}_{4}\right)$ and to a smaller extent metaphosphoric acid $\left(\mathrm{HPO}_{3}\right)$ from a precursor ion ${ }^{[3-9]}$. The elimination of phosphoric acid represents the main dissociation channel for both singly and multiply charged phosphopeptides. However, as it facilitates the identification of phosphorylation, it impedes the identification of the sequence and hinders the characterisation of phosphorylated sites ( $b$ and y product ions also undergo detachment of phosphoric acid). Although the data-dependent mode of operation with an additional tandem mass spectrometry cycle ${ }^{[3]}\left(\mathrm{CID}\right.$ of $\left.\left[\mathrm{M}+\mathrm{nH}-\mathrm{H}_{3} \mathrm{PO}_{4}\right]^{\mathrm{n+}}\right)$ was used with the goal of phosphorylation site assignment, it has been shown that this can be misleading and can cause assignments errors ${ }^{[6]}$.

Although the CID tandem mass spectrometry is a powerful and most widely used method for phosphorylation analysis, some gas-phase chemistry issues are causing difficulties in proper sequence assignments, and consensus concerning the gas-phase fragmentation pathways for phosphate loss has not yet been reached.

The observation of the nonsequence loss of $98 \mathrm{Da}$ during CID that may be assigned to loss of the phosphoric acid has been reported ${ }^{[10,11]}$. Furthermore, it was hypothesised that the 98-Da loss could be the result of $\mathrm{HPO}_{3}$ loss from phosphorylated site and $\mathrm{H}_{2} \mathrm{O}$ loss from nonphosphorylated residue (carboxylic or hydroxylic) ${ }^{[3,7,8]}$. In addition, Palumbo and Reid ${ }^{[6]}$ showed that the gas-phase phosphate group is scrambled among potential phosphorylation sites during CID in the ion trap.

Regarding the dissociation mechanisms, it was a common thought that the loss of $\mathrm{H}_{3} \mathrm{PO}_{4}$ occurs via a relatively low-energy $\beta$-elimination pathway (pathway A in Scheme 1) ${ }^{[8,9]}$, which produces a dehydroalanine or dehydrothreonine residue. Tandem mass spectrometry study by Reid et al. ${ }^{[12]}$ concluded that $\mathrm{H}_{3} \mathrm{PO}_{4}$ loss from protonated $\mathrm{O}$-phosphoserine yields a three-membered aziridine ring and a five-membered oxazoline ring. However, $a b$ initio data at the MP2(FC)/6-31G(d)//HF/6-31G(d) level of theory (from the same study ${ }^{[12]}$ ) predicted the $\beta$-elimination pathway 


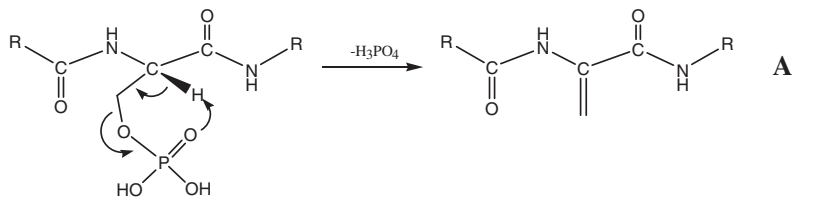<smiles>[2H]NC(=O)C1CN1C(=O)COP(O)(O)(O)OCC#C</smiles>

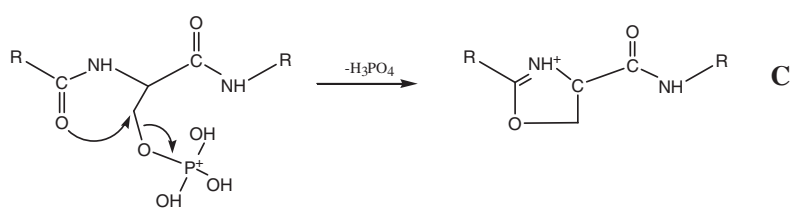<smiles>[2H]NC(=O)C1COC(P)=N1</smiles><smiles>C=C(N=C(O)P)C(=O)NPCC</smiles>

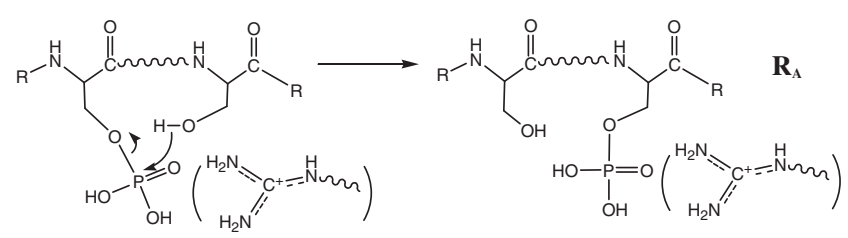

Scheme 1.

(threshold of $85 \mathrm{~kJ} \mathrm{~mol}^{-1}$ ) to be preferred over a three-membered aziridine ring formation (pathway $B$ in Scheme 1) by a few $\mathrm{kJ} \mathrm{mol}^{-1}$. Disagreement between experimental and theoretical results was explained by problems with geometry optimisation at the low levels of theory. Finally, they suggested that in larger peptides, phosphate loss may occur through intramolecular nucleophilic substitution $\left(S_{N} 2\right)$ and $E_{2}$ elimination (pathways $C$ and $D$ in Scheme 1$)^{[12]}$.

Gronet et al. ${ }^{[13]}$ computationally examined $\mathrm{H}_{3} \mathrm{PO}_{4}$ loss from a small model system (protonated glycylphosphoserine $N$-methyl amide) at the MP2/6-311+G(d,p)//MP2/6-31+G(d) level of theory. Pathways $A$ and $C$ (Scheme 1) were considered together with two additional paths, which included N-terminal assistance/cyclisation, specific for systems where pSer is at the second position in the peptide. Similar barriers for all paths were reported (from 154 to $166 \mathrm{~kJ} \mathrm{~mol}^{-1}$ ), suggesting that phosphoric acid loss can occur simultaneously through multiple paths.

Mechanistic insights were recently made by Palumbo et al. ${ }^{[5]}$, where the observation of the characteristic product loss of formaldehyde $\left(\mathrm{CH}_{2} \mathrm{O}, 30 \mathrm{Da}\right)$ upon the $\mathrm{MS}^{3}$ of the peptide containing pSer was considered as experimental evidence pointing toward charge-directed $\mathrm{S}_{\mathrm{N}} 2$ mechanism in systems with limited mobility of the ionising proton (LPM; $C_{L P M}$ in Scheme 1). In addition, they proposed the mechanism for the gas-phase phosphate group rearrangement $\left(R_{A} \text { in Scheme } 1\right)^{[6]}$.

So far, few of the proposed pathways ( $A, B$ and $C$ in Scheme 1) have been computationally assessed ${ }^{[12,13]}$, and only reaction thresholds in the mobile proton environment were provided. This work computationally assesses all previously proposed mechanisms (Scheme 1), together with new ones presented in Scheme 2. Presented pathways are tested on a peptide level in the context of the charge-remote and charge-directed fragmentation as well as in situations of different proton mobility. Unravelled thermodynamics (potential energy surfaces) provides a basis for discussing kinetics aspects of the gas-phase unimolecular dissociation. Elucidated phosphopeptide fragmentation behaviour is further discussed in the context of predicting tandem MS ion abundances.

\section{COMPUTATIONAL METHODS}

To estimate the thermodynamic and kinetic aspects of the main fragmentation and the rearrangement pathways of phosphorylated peptides, we used a combination of quantum mechanics (QM) and the Rice-Ramsperger-Kassel-Marcus (RRKM) theory modelling. The potential energy surfaces of the proposed pathways were first established on small model systems $\left(\mathrm{CH}_{3} \mathrm{CO}-\mathrm{pSer}-\mathrm{NHCH}_{3}-\right.$ phosphate loss and phosphate group rearrangement, $\mathrm{CH}_{3} \mathrm{OH}$ and $\mathrm{CH}_{3} \mathrm{OPO}_{3} \mathrm{H}_{2}$-phosphate group rearrangement) and then

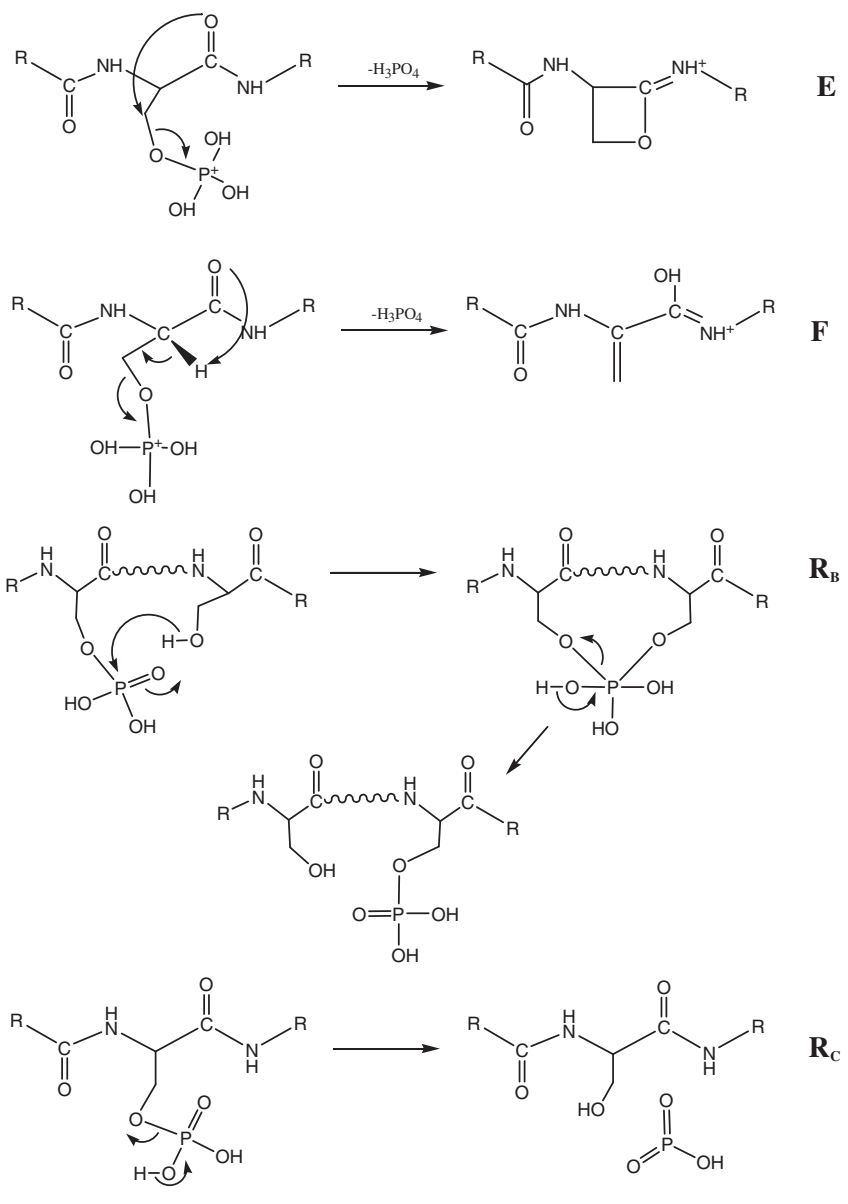

Scheme 2. 
further evaluated on test peptides GAILpSGAILR and HYGIpTSPISLAAPK from Palumbo et al. ${ }^{[5]}$ and Palumbo and Reid ${ }^{[6]}$.

Calculations for various model system structures were performed at the B3LYP/6-31G(d) level. Both the functional and the basis set represent a good compromise for obtaining satisfactory geometries and approximate relative energies in the theoretical studies of similar systems ${ }^{[14-17]}$. Stationary points (i.e. the minima and transition states on the potential energy surface) were identified by the harmonic frequency analysis. Transition state structures were additionally tested by the intrinsic reaction coordinate analysis.

The potential energy surface of the test peptides was sampled by a combination of quenched dynamics and simulated annealing. The molecular dynamics simulations at $800 \mathrm{~K}$ for $30 \mathrm{ps}$ were followed by slow cooling at $200 \mathrm{~K}$ for $10 \mathrm{ps}$ and by geometry optimisation using a steepest descent approach. Five hundred structures were generated with this procedure for each peptide variant. The structures within $\sim 41 \mathrm{~kJ} \mathrm{~mol}^{-1}\left(10 \mathrm{kcal} \mathrm{mol}^{-1}\right)$ from the lowest energy conformer were selected as the candidate group. The candidate group structures were reoptimised using PM6 semiempirical method ${ }^{[18]}$. The lowest energy structure found was considered as representative structure and further treated with two layer (QM/QM) ONIOM treatment ${ }^{[19]}$. In the combined $\mathrm{QM} / \mathrm{QM}$ treatment, the reaction site (usually $-\mathrm{CH}_{2} \mathrm{CO}$-pSer- $\mathrm{NHCH}_{2}$ - part + additional basic group) was described at the B3LYP/6-31G(d) level of theory, whereas the rest of the peptide was described using PM6 method.

To obtain a more accurate description of dissociation energies, particularly because it was found that for $\mathrm{S}_{\mathrm{N}} 2$ reactions B3LYP/6$31 \mathrm{G}(\mathrm{d})$ underestimates barrier heights ${ }^{[20,21]}$, single point calculations at the MP2(FC)/6-31++G(d,p)//B3LYP/6-31G(d):PM6 level were used. Energies computed at the MP2(FC)/6-31++G(d,p)// B3LYP/6-31G(d) level have shown smallest deviation when several higher basis sets and levels of theory were evaluated against G3(MP2)//B3LYP (G3MP2B3) composite computational protocol ${ }^{\text {[22] }}$ on a restricted number of model system molecules.

All molecular dynamics simulations were performed using the HyperChem (Waterloo, Ontario, Canada) with AMBER 99 force field, whereas QM calculations were performed using the GAUSSIAN 03 and $09^{[23]}$. Kinetic insights into fragmentation and rearrangement pathways were achieved by using RRKM formalism in the MassKinetics application ${ }^{[24]}$. Outputs from QM calculations (energetic and rovibrational data) were used to estimate unimolecular rate constants over a range of internal energies.

\section{RESULTS AND DISCUSSION}

\section{Neutral loss of $\mathrm{H}_{3} \mathrm{PO}_{4}$}

The evaluation of neutral $\mathrm{H}_{3} \mathrm{PO}_{4}$ loss mechanisms presented on Schemes 1 and 2 was performed using the GAILpSGAILR peptide from Palumbo et al. ${ }^{[5]}$. Proposed pathways were tested in the context of the proton mobility. The limited proton mobility occurs in peptides where the number of basic amino acids is greater or equal to the number of ionising protons, and a large energy is needed to mobilise the proton to the energetically less favoured protonation site ${ }^{[25-27]}$.

The mobile proton environment. In the mobile proton environment, the test peptide will be doubly protonated, and several protonation sites are accessible in the low-energy CID range ${ }^{[25-27]}$. Here, we presume that during vibrational excitation, one ionising proton will migrate to one of the phospho-group oxygen whereas the other will remain located on the highly basic guanidine group of the C-terminal arginine. The protonation of the phospho-group is very useful because such positive group becomes suitable for a nucleophilic attack. With surrounding nucleophiles (N-terminal carbonyl oxygen, phosphorylated amino acid amide nitrogen or carbonyl oxygen), there is potential for three $S_{N} 2$ reactions, where a lone pair from the nucleophile attacks the electron-deficient $\beta$-carbon of the phosphorylated amino acid and binds to it, expelling the $\mathrm{H}_{3} \mathrm{PO}_{4}$ group. The first one (mechanism $\mathrm{C}$ in Scheme 1) represents the nucleophilic attack of the N-terminal carbonyl oxygen and the formation of a cyclic five-membered oxazoline product ion. In the second mechanism (mechanism E in Scheme 2), the phosphorylated amino acid carbonyl oxygen is responsible for nucleophilic attack, thus forming an oxetane ring. The third mechanism (mechanism B in Scheme 1) ) yields a three-membered aziridine ring through the nucleophilic attack of the phosphorylated amino acid amide nitrogen. We also need to consider competing $E_{2}$ elimination involving the nucleophilic N-terminal carbonyl oxygen (mechanism D, Scheme 1) or the phosphorylated amino acid carbonyl oxygen (mechanism F, Scheme 2) attack on the $\alpha$-carbon hydrogen atom, resulting in the formation of a dehydroalanine (in pSer) or a dehydroamino2-butyric acid (in pThr).

The dissociation thresholds are listed in Table 1 (calculated total energies (in $E_{\mathrm{h}}$ ) can be found in supporting data file). Summarising the presented data, we can notice that highest barriers (204.9 and $251.9 \mathrm{~kJ} \mathrm{~mol}^{-1}$ ) can be associated with $\mathrm{E}_{2}$ mechanisms (pathways $\mathrm{D}$ and $\mathrm{F}$ ). $\mathrm{S}_{\mathrm{N}} 2$ pathways have a lower threshold, suggesting nucleophilic substitution as a favourable way for $\mathrm{H}_{3} \mathrm{PO}_{4}$ expulsion. Thermodynamically, the most favoured pathway is pathway $C\left(154.4 \mathrm{~kJ} \mathrm{~mol}^{-1}\right)$, in agreement with the previous results of Gronet et al. ${ }^{[13]}$, which suggest a reaction threshold of $154 \mathrm{~kJ} \mathrm{~mol}^{-1}$.

Having in mind that the average low-energy CID amount of energy transferred into vibrational modes is in the range of few electron volts $(\mathrm{eV})^{[28]}$, the time component of mechanisms needs to be taken into account. Calculated unimolecular reaction rates (by RRKM theory) show that for reaching both millisecond and microsecond time range, pathways $C$ requires least energy (996 and $1537 \mathrm{~kJ} \mathrm{~mol}^{-1}$, respectively; Figure 1).

The obtained results suggest that the neutral loss of the phosphoric acid follows an $\mathrm{S}_{\mathrm{N}}$ 2-type mechanism, mainly pathway $\mathrm{C}$ (Scheme 1). On the other hand, elimination reactions would yield a negligible amount of product ions. The finding is consistent with the performed deuterium-labelling experiment, which found that the minor part of the neutral loss product ion population can be assigned to the elimination mechanism ${ }^{[5]}$. Here, it is important to notice that in real-life samples, phosphate loss mechanism would be most probably initiated by the nucleophilic attack of surrounding carbonyl oxygen as in pathways $C$ and $E$. However, depending on the gas-phase peptide secondary structure, it is also possible that nucleophilic attack could be initiated by some other neighbouring nucleophilic group (e.g. amino, carboxylic, etc.) whose proximity is a consequence of the peptide's secondary structure.

The energetic and the kinetic properties of the phosphoric acid neutral loss pathways match the lowest energy peptide bond dissociation pathways (formation of $\mathrm{b}$ and $\mathrm{y}$ ions) whose average internal energy values for similar size peptides are approximately 870 and $1670 \mathrm{~kJ} \mathrm{~mol}^{-1}$ (for the millisecond and the microsecond time range) ${ }^{[29]}$. This suggests the appearance of $\mathrm{H}_{3} \mathrm{PO}_{4}$ neutral loss 
Table 1. Relative energies $\left(\mathrm{kJ} \mathrm{mol}^{-1}\right)$ of transition states calculated on the GAILpSGAILR test peptide

\begin{tabular}{llll} 
Pathway & Reaction type & Relative energy & \\
\hline & & B3LYP/6-31G(d):PM6 & MP2(FC)/6-31++G(d,p) //B3LYP/6-31G(d):PM6 \\
B & $\mathrm{S}_{\mathrm{N}} 2$ & 189.5 & 187.9 \\
$\mathrm{C}$ & $\mathrm{S}_{\mathrm{N}} 2$ & 140.7 & 154.4 \\
$\mathrm{D}$ & $\mathrm{E}_{2}$ & 202.9 & 204.9 \\
$\mathrm{E}$ & $\mathrm{S}_{\mathrm{N} 2}$ & 193.9 & 190.4 \\
$\mathrm{~F}$ & $\mathrm{E}_{2}$ & 250.7 & 251.9 \\
\hline
\end{tabular}

The relative energies were calculated with respect to the most stable peptide conformation.

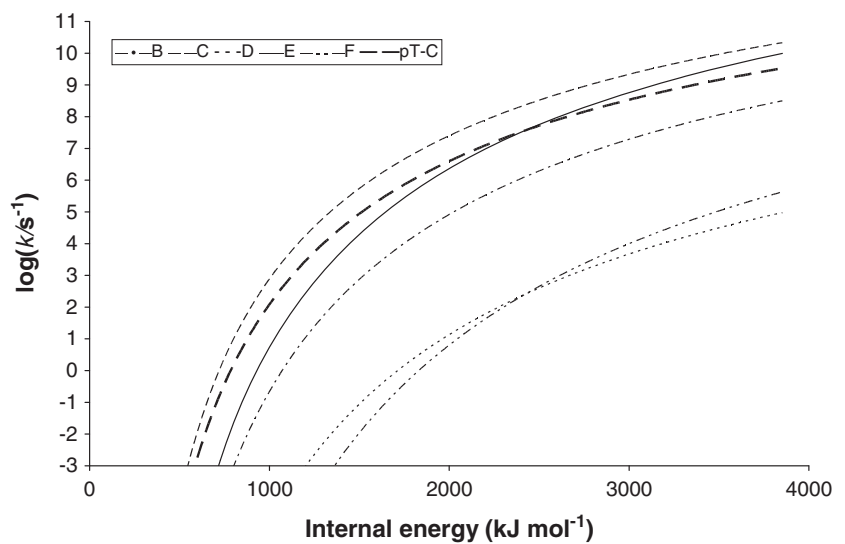

Figure 1. RRKM theory unimolecular reaction rate constants for the phosphoric acid neutral loss in the mobile proton environment (GAILpSGAILR peptide). Bold dashed line ( $\mathrm{pT}-\mathrm{C}$ ) represents mechanism $\mathrm{C}$ unimolecular rate energy dependence for GAILpTGAILR peptide.

product and backbone cleavage fragments during low-energy CID, as observed in the low-energy CID spectra of phosphopeptides ${ }^{[5,6]}$.

In all suggested pathways, charge (proton) remains on a peptide backbone, leaving the mobile proton environment of the neutral loss product ion unaffected, which is also in agreement with experimental observations where $\mathrm{MS}^{3}$ spectra show extensive fragmentation ${ }^{[5,6]}$.

Regarding the differences in fragmentation energetic and the dynamics of phosphoserine (pS) versus phosphothreonine (pT), it was shown that the magnitudes of $\mathrm{H}_{3} \mathrm{PO}_{4}$ neutral loss from pS containing peptides are higher than those from their analogs that contain $\mathrm{pT}^{[5]}$. Mechanism $\mathrm{C}$, suggested here as a main pathway for $\mathrm{H}_{3} \mathrm{PO}_{4}$ neutral loss in the mobile proton environment neutral, was tested on GAILPTGAILR peptide. Replacing pS with PT residue leaves the dissociation threshold roughly the same $\left(1 \mathrm{~kJ} \mathrm{~mol}^{-1}\right.$ increase). However, the residue substitution is reflected in fragmentation dynamics (Figure 1). The rate-energy dependencies for GAILpSGAILR and GAILPTGAILR diverge, and the rate constant rises slower for GAILPTGAILR. This suggests that the phosphate loss from peptides containing $\mathrm{pT}$ is less abundant than those from $\mathrm{pS}$ on a microsecond and millisecond time scale, which is in good agreement literature data ${ }^{[5]}$.

The limited proton mobility environment. In the limited proton mobility environment, ionising proton during the low-energy CID remains conserved on side chain of the basic amino acid [25-27]; that is, our test peptide will be singly protonated, and ionising proton will be placed on a guanidino group of C-terminal arginine whereas the phospho-group will stay neutral. Phosphorylated peptides readily lose phosphoric acid in systems with limited mobility of the ionising proton ${ }^{[4-6]}$. Charge-remote mechanism associated with $\mathrm{H}_{3} \mathrm{PO}_{4}$ expulsion was $\beta$-elimination pathway (mechanism A in Scheme 1). However, Palumbo et al. ${ }^{[5]}$ provided experimental arguments for charge-directed (by assistance of protonated guanidino group) $\mathrm{S}_{\mathrm{N}} 2$ mechanism ( $\mathrm{C}_{\mathrm{LPM}}$ in Scheme 1). Here, we consider $\beta$-elimination as the chargeremote mechanism as well as several mechanisms influenced by noncovalent interaction between the phosphate group and the arginine guanidino group (the charged-directed mechanism). The positively charged guanidinium group can interact noncovalently with the phosphate group, thus having a potential for withdrawing electrons and creating an electrophilic group suitable for $S_{N} 2$ nucleophilic attack. The scenario is the same as in the mobile proton environment ( $B$ and $E$ in Schemes 1 and 2). However, instead of the protonated phosphate group, the interaction between the neutral phosphate and the protonated basic (e.g. guanidino) group takes place (mechanisms are denoted as $B_{L P M}$ and $E_{L P M}$ ). Thus, three $S_{N} 2$ reactions where surrounding nucleophiles attack $\beta$-carbon of the phosphorylated amino acid are considered.

Recently, Bythell et al. ${ }^{[30]}$ demonstrated the mobilisation of the C-terminal carboxylic acid proton, which enabled fragmentation pathways in systems with limited proton mobility. Accordingly, the stabilisation of the protonated phosphate group with a proton from the guanidino or the C-terminal carboxylic group was considered. However, during several optimisation attempts, the proton was constantly migrating to its original site (guanidine or C-terminal carboxylic group), and we were unable to locate a minimum with the protonated phosphate group.

Calculated reaction barriers (Table 2 ) suggest $C_{\text {LPM }}$ mechanism as the lowest energy pathway. Regarding reaction threshold for the $\beta$-elimination mechanism, it is interesting to notice that our value is higher than that of Gronet et al. ${ }^{[13]}\left(166 \mathrm{~kJ} \mathrm{~mol}^{-1}\right)$ or Reid et al. ${ }^{[12]}\left(85 \mathrm{~kJ} \mathrm{~mol}^{-1}\right)$. However, in both cases, the $\beta$-elimination mechanism was tested in the mobile proton environment, which enabled the formation of additional hydrogen bonds that probably contributed to the stabilisation of the transition state, thus lowering the reaction threshold. Furthermore, Reid et al. ${ }^{[12]}$ suggested that their value is probably underestimated because of problems with geometry optimisation at the low levels of theory. Calculated RRKM reaction rates show that at the millisecond (internal energy of $1035 \mathrm{~kJ} \mathrm{~mol}^{-1}$ ) and microsecond (internal energy of $1600 \mathrm{~kJ} \mathrm{~mol}^{-1}$ ) time scale $C_{\mathrm{LPM}}$ mechanism is dominant (Figure 2).

Replacing pS with $\mathrm{pT}$ residue has a small effect on dissociation threshold $\left(5 \mathrm{~kJ} \mathrm{~mol}^{-1}\right.$ increase) and causes the dissociation rate-energy dependencies for GAILPSGAILR and GAILPTGAILR to diverge (Figure 2). GAILPSGAILR rate constant rises quicker through the entire internal energy range, but the difference is not as large as in the mobile proton environment (Figure 1). 
Table 2. Relative energies $\left(\mathrm{kJ} \mathrm{mol}^{-1}\right)$ of transition states calculated on the GAILPSGAILR test peptide

\begin{tabular}{llll} 
Pathway & Reaction type & Relative energy & \\
\hline & & B3LYP/6-31G(d):PM6 & MP2(FC)/6-31++G(d,p) //B3LYP/6-31G(d):PM6 \\
$A$ & $\beta$-elimination & 199.2 & 208.6 \\
$B_{L P M}$ & $\mathrm{~S}_{\mathrm{N}} 2$ & 247.3 & 220.2 \\
$C_{\text {LPM }}$ & $\mathrm{S}_{\mathrm{N}} 2$ & 156.4 & 153.8 \\
E $_{\text {LPM }}$ & $\mathrm{S}_{\mathrm{N}} 2$ & 270.2 & 274.6
\end{tabular}

The relative energies were calculated with respect to the most stable peptide conformation.

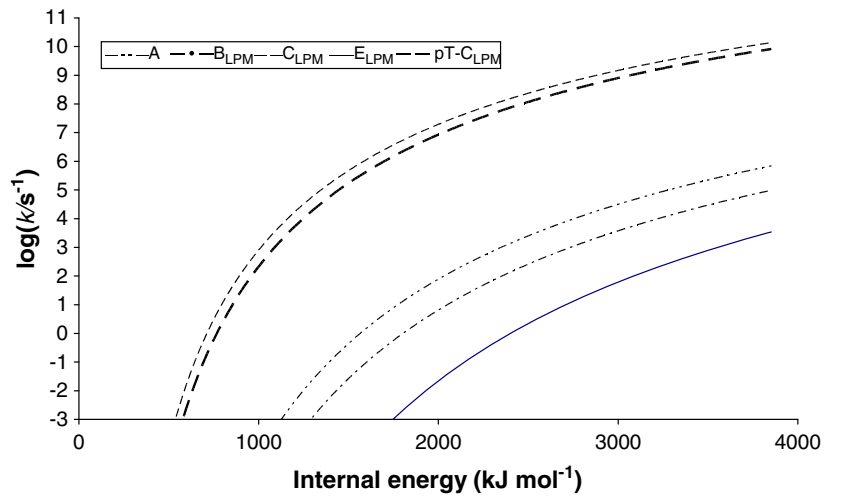

Figure 2. RRKM theory unimolecular reaction rate constants for the phosphoric acid neutral loss in the limited proton mobility environment (GAILpSGAILR peptide). Bold dashed line ( $\mathrm{pT}-\mathrm{C}_{\mathrm{LPM}}$ ) represents mechanism $C$ unimolecular rate energy dependence for GAILPTGAILR peptide.

The latter is in accordance with the finding that the ratio of ion abundances of $\mathrm{H}_{3} \mathrm{PO}_{4}$ neutral loss from $\mathrm{pS}$ versus analogous pT containing peptides is lower in the limited proton mobility environment ${ }^{[5]}$.

Overall, our results suggest that in the limited proton mobility environment, the neutral loss of the phosphoric acid is a consequence of charge-directed fragmentation pathway. A fragmentation mechanism benefits from the presence of a charged group in two ways: first, by making the $\beta$-carbon of the phosphorylated residue electron deficient and thus susceptible to nucleophilic attack and, second, by assisting the $\mathrm{H}_{2} \mathrm{PO}_{4}^{-}$leaving group and acting as a possible neutraliser during the postdissociation event to form $\mathrm{H}_{3} \mathrm{PO}_{4}$.

In a context of $\mathrm{MS}^{2}$ ion abundances, the available RRKM modelling data of peptide bond cleavage ${ }^{[28,31-33]}$, although on smaller peptides, suggest internal energy window from 1000 to $1700 \mathrm{~kJ} \mathrm{~mol}^{-1}$ for the millisecond time frame, thus indicating a possibility for the abundant and sometimes dominant neutral loss product ion, which is in agreement with experimental data. ${ }^{[4-6]}$

\section{Phosphate group rearrangement}

Recent investigations showed that in the limited proton mobility environment, phospho-peptides with hydroxyl containing amino acids can undergo transfer of the phosphate group from phosphorylated residue to an unmodified hydroxyl site ${ }^{[6]}$. This is an important issue that may interfere with the proper characterisation of the phosphate group especially having in mind that on average $40 \%$ of tryptic peptides will contain two amino acids with hydroxyl group (calculated from the UniProtKB/Swiss-Prot protein knowledgebase statistics). However, very recent experimental studies suggested that although some phosphopeptides undergo intramolecular phosphate transfer, it does not affect the identification of the correct phosphosites ${ }^{[34,35]}$.

Here, three rearrangement mechanisms were considered: the first mechanism proposed by Palumbo and Reid ${ }^{[6]}$ involves nucleophilic attack by the hydroxyl oxygen of a nonphosphorylated residue on the phosphorus atom of a phosphorylated residue accompanied with concerted proton transfer $\left(R_{A}\right.$ in Scheme 1). Note that this mechanism requires the contact of two residues involved in the rearrangement. The second mechanism also requires contact between a hydroxylic and a phosphoric amino acid. However, here a contact within the reaction complex is more specific requiring the trigon-bipyramidal geometry. The mechanism is initiated by proton transfer from the nonphosphorylated residue to the phospho-group oxygen, which is followed by the phospho-group rearrangement as well as the proton transfer to the releasing residue oxygen $\left(R_{B}\right.$ in Scheme 2$)$. The third mechanism considered does not require direct contact between a hydroxylic and a phosphoric amino acid because proton transfer from the phosphate group hydroxyl to the ester oxygen leads to the hydroxylic group and $\mathrm{HPO}_{3}$ formation. $\mathrm{HPO}_{3}$ molecule can sample peptide backbone and locate another hydroxylic residue where the reverse reaction will take place $\left(R_{C}\right.$ in Scheme 2).

Taking into account the limited proton mobility environment where the phosphate group scrambling predominates ${ }^{[6]}$, possible rearrangement mechanisms were tested in the limited proton mobility environment. Pathways that require direct contact between two hydroxylic amino acids $\left(\mathrm{R}_{\mathrm{A}}\right.$ and $\left.\mathrm{R}_{\mathrm{B}}\right)$ were tested on a methanol-methyl phosphate model system $\left(\mathrm{CH}_{3} \mathrm{OH}\right.$ and $\mathrm{CH}_{3} \mathrm{O}$ $\mathrm{PO}_{3} \mathrm{H}_{2}$ ), whereas pathway $\mathrm{R}_{\mathrm{C}}$ with $\mathrm{HPO}_{3}$ expulsion was tested on $\mathrm{CH}_{3} \mathrm{CO}$-pSer- $\mathrm{NHCH}_{3}$ model system. Evaluation in the peptide environment was performed on test peptide HYGIPTSPISLAAPK, where the phosphate group transfer from Thr-5 to Ser-9 residue was observed ${ }^{[6]}$.

The potential energy profiles together with the optimised structures for the rearrangement mechanisms are shown in Figure 3. The lowest activation energy is associated with pathway $R_{B}\left(178 \mathrm{~kJ} \mathrm{~mol}^{-1}\right)$, whereas the other pathways require 40 to $60 \mathrm{~kJ} \mathrm{~mol}^{-1}$ more energy. Therefore, on thermodynamic grounds, mechanism $R_{B}$ should be favoured.However, the calculated unimolecular dissociation rate constants show competition between pathways $R_{B}$ and $R_{C}$ and at the millisecond time scale suggest a slight dominance of pathway $R_{C}$ (Figure 4). Moreover, bearing in mind that the mechanism $R_{B}$ requires specific (trigon-bipyramidal geometry) contact between hydroxylic and phosphoric amino acid (whereas $\mathrm{R}_{\mathrm{C}}$ mechanism does not), it seems that the phospho-group rearrangement will mainly proceed via pathway $R_{C}$. At this point, it 


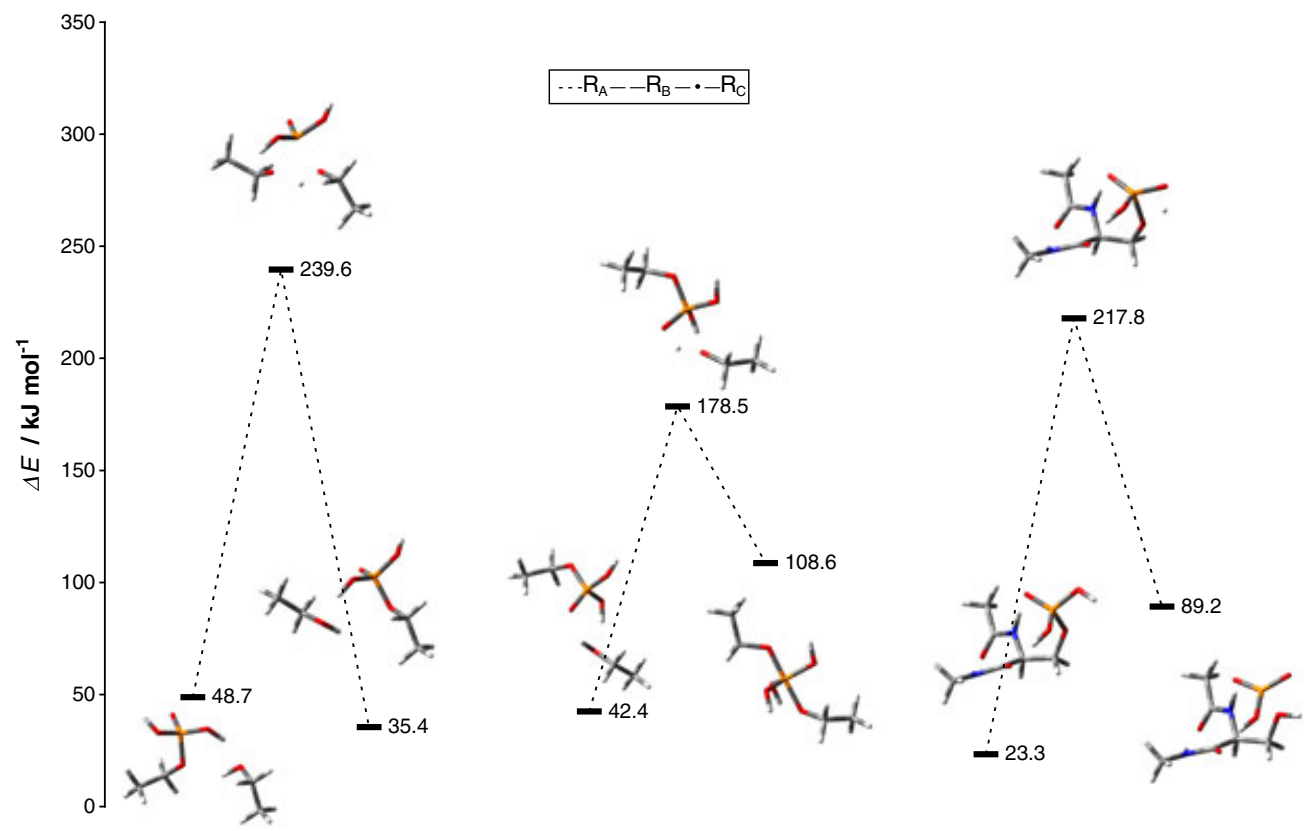

Figure 3. Schematic representation of $R_{A}, R_{B}$ and $R_{C}$ mechanism potential energy profiles. Test peptide (HYGIpTSPISLAAPK) potential energy profiles were obtained at the MP2(FC)/6-31++G(d,p)//B3LYP/6-31G(d):PM6 level of theory. Energies are relative to the test peptide lowest energy structure. Peptide structures can be found in supporting data file.

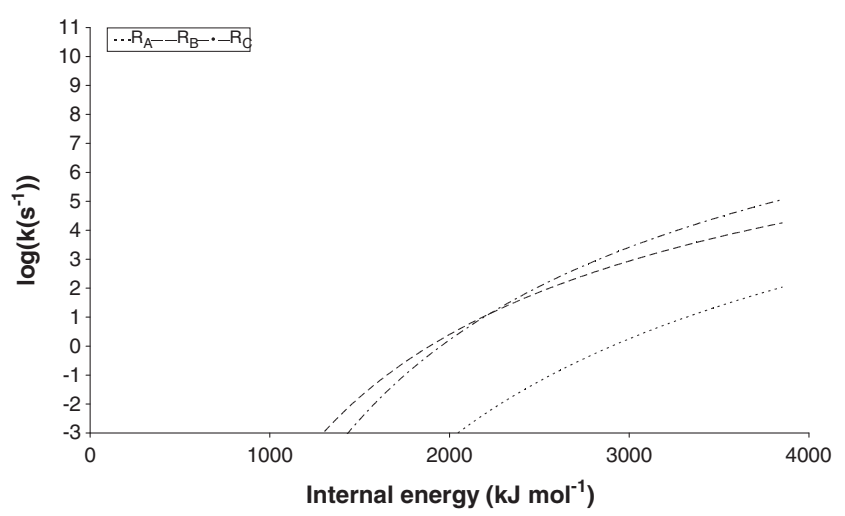

Figure 4. RRKM theory unimolecular reaction rate constants for the phospho-group rearrangement (HYGIpTSPISLAAPK test peptide).

is interesting to note that pathway $R_{C}$ can explain the occasional observation of the low abundant signal associated with the loss of metaphosphoric $\left(\mathrm{HPO}_{3}\right)$ acid in phosphorylated peptides ${ }^{[7,8]}$.

According to the RRKM calculations (Figures 2 and 4), the fastest phosphate group rearrangement reaction occurs at the millisecond time scale at the same internal energy when the phosphate loss reaction reaches the microsecond time scale. Furthermore, the mechanisms $R_{B}$ and $R_{C}$ in the RRKM slope are not steeply going toward the microsecond time scale, implying a low abundance of the rearrangement product ions, which can be probably observed at the millisecond time scale, consistent with the experimental observations. ${ }^{[6]}$

\section{CONCLUSION}

The molecular modelling work presented here provides insight into the energetic and kinetic aspects of the gas-phase unimolecular dissociation of phosphorylated peptides. Important findings can be summarised as follows:

The observed neutral phosphate loss of phosphorylated peptides is mainly the result of the charge-directed (either by a mobile proton or by a positively charged side chain of some basic residue) $\mathrm{S}_{\mathrm{N}} 2$ mechanism. Phosphorylated residue $\mathrm{N}$ terminal carbonyl acts as nucleophile displacing phosphate on the $\beta$-carbon and yielding a cyclic five-membered oxazoline product ion.

Unimolecular reaction rates indicate that the dissociation product abundances are dependent on the proton mobility. Under the mobile proton environment, phosphoric acid neutral loss product ion competes with typical peptide backbone cleavage fragments, whereas in the limited proton mobility environment the neutral loss product ion could be dominant.

The fragmentation dynamics of $\mathrm{pS}$ versus $\mathrm{pT}$ containing peptides suggest that the phosphate loss from pT containing peptides is less prominent than from those containing pS.

During the low-energy CID of phosphorylated peptides in the millisecond time range phosphate group rearrangement may happen and yield low abundant rearrangement product ions. The resulting rearrangement products can lead to a false characterisation of the phosphate group.

\section{Acknowledgements}

Helpful discussions with Laboratory members are gratefully acknowledged. The Ministry of Science, Education and Sports of Republic of Croatia supported this work (grant no. 098-09829152945).

\section{Supporting Information}

Supporting information may be found in the online version of this article. 


\section{References}

[1] R. Aebersold, M. Mann. Mass spectrometry-based proteomics. Nature 2003, 422, 198.

[2] M. Abu-Farha, F. Elisma, H. Zhou, R. Tian, H. Zhou, M. S. Asmer, D. Figeys. Proteomics:From Technology Developments to Biological Applications. Anal. Chem. 2009, 81, 4585.

[3] E. J. Chang, V. Archambault, D. T. McLachlin, A. N. Krutchinsky, B. T. Chait. Analysis of Protein Phosphorylation by Hypothesis-Driven Multiple-Stage Mass Spectrometry. Anal. Chem. 2004, 76, 4472.

[4] S. C. Moyer, R. J. Cotter, A. S. Woods. Fragmentation of Phosphopeptides by Atmospheric Pressure MALDI and ESI/Ion Trap Mass Spectrometry. J. Am. Soc. Mass Spectrom. 2002, 13, 274.

[5] A. M. Palumbo, J. J. Tepe, G. E. Reid. Mechanistic Insights into the Multistage Gas-Phase Fragmentation Behavior of Phosphoserineand Phosphothreonine-Containing Peptides. J. Proteome Res. 2008, 7, 771.

[6] A. M. Palumbo, G. E. Reid. Evaluation of Gas-Phase Rearrangement and Competing Fragmentation Reactions on Protein Phosphorylation Site Assignment Using Collision Induced Dissociation-MS/MS and MS. Anal. Chem. 2008, 80, 9735.

[7] S. C. Moyer, C. E. VonSeggern, R. J. Cotter. Fragmentation of Cationized Phosphotyrosine Containing Peptides by Atmospheric Pressure MALDI/lon Trap Mass Spectrometry. J. Am. Soc. Mass Spectrom. 2003, 14, 581.

[8] J. P. DeGnore, J. Quin. Fragmentation of Phosphopeptides in an Ion Trap Mass Spectrometer. J. Am. Soc. Mass Spectrom. 1998, 9, 1175.

[9] A. Tholey, J. Reed, W. D. Lehmann. Electrospray Tandem Mass Spectrometric Studies of Phosphopeptides and Phosphopeptide Analogues. J. Mass Spectrom. 1999, 34, 117.

[10] A. Schlosser, R. Pipkorn, D. Bossemeyer, W. D. Lehmann. Analysis of Protein Phosphorylation by a Combination of Elastase Digestion and Neutral Loss Tandem Mass Spectrometry. Anal. Chem. 2001, 73, 170.

[11] S. A. Carr, M. J. Huddleston, R. S. Annan. Selective detection and sequencing of phosphopeptides at the femtomole level by mass spectrometry. Anal. Biochem. 1996, 239, 180.

[12] G. E. Reid, R. J. Simpson, R. A. J. O'Hair. Leaving Group and Gas Phase Neighboring Group Effects in the Side Chain Losses from Protonated Serine and its Derivatives. J. Am. Soc. Mass Spectrom. 2000, 11, 1047.

[13] S. Gronet, K. H. Li, M. Horiuchi. Manipulating the Fragmentation Patterns of Phosphopeptides via Gas-Phase Boron Derivatization: Determining Phosphorylation Sites in Peptides with Multiple Serines. J. Am. Soc. Mass Spectrom. 2005, 16, 1905.

[14] K. A. Herrmann, V. H. Wysocki, E. R. Vorpagel. Computational Investigation and Hydrogen/Deuterium Exchange of the Fixed Charge Derivative Tris(2,4,6-Trimethoxyphenyl) Phosphonium: Implications for the Aspartic Acid Cleavage Mechanism. J. Am. Soc. Mass Spectrom. 2005, 16, 1067.

[15] M. Rožman. Aspartic acid side chain effect - experimental and theoretical insight. J. Am. Soc. Mass Spectrom. 2007, 18, 121.

[16] B. Paizs, S. Suhai. Combined quantum chemical and RRKM modeling of the main fragmentation pathways of protonated GGG. I. Cis-trans isomerization around protonated amide bonds. Rapid Commun. Mass Spectrom. 2001, 15, 2307.

[17] B. Paizs, S. Suhai. Combined quantum chemical and RRKM modeling of the main fragmentation pathways of protonated GGG. II. Formation of b2, y1, and y2 ions. Rapid Commun. Mass Spectrom. 2002, $16,375$.

[18] J. J. P. Stewart. Optimization of parameters for semiempirical methods V: Modification of NDDO approximations and application to 70 elements. J. Mol. Model. 2007, 13, 1173.

[19] T. Vreven, K. Morokuma. On the Application of the IMOMO (Integrated Molecular Orbital C Molecular Orbital) Method. J. Comp. Chem. 2000, 21, 1419.

[20] R. A. Ochran, E. Uggerud. $\mathrm{S}_{\mathrm{N}} 2$ reactions with allylic substratesTrends in reactivity. Int. J. Mass Spectrom. 2007, 265, 169.
[21] M. N. Glukhovtsev, R. D. Bach, A. Pross, L. Radom. The performance of B3-LYP density functional theory in describing $S_{N} 2$ reactions at saturated carbon. Chem. Phys. Lett. 1996, 260, 558.

[22] A. G. Baboul, L. A. Curtiss, P. C. Redfern, K. Raghavachari. Gaussian-3 theory using densitiy functional geometries and zero-point energies. J. Chem. Phys. 1999, 110, 7650.

[23] Gaussian 03 \& 09. M. J. Frisch, G. W. Trucks, H. B. Schlegel, G. E. Scuseria, M. A. Robb, J. R. Cheeseman, J. A. Montgomery Jr., T. Vreven, K. N. Kudin, J. C. Burant, J. M. Millam, S. S. Iyengar, J. Tomasi, V. Barone, B. Mennucci, M. Cossi, G. Scalmani, N. Rega, G. A. Petersson, H. Nakatsuji, M. Hada, M. Ehara, K. Toyota, R. Fukuda, J. Hasegawa, M. Ishida, T. Nakajima, Y. Honda, O. Kitao, H. Nakai, M. Klene, X. Li, J. E. Knox, H. P. Hratchian, J. B. Cross, C. Adamo, J. Jaramillo, R. Gomperts, R. E. Stratmann, O. Yazyev, A. J. Austin, R. Cammi, C. Pomelli, J. W. Ochterski, P. Y. Ayala, K. Morokuma, G. A. Voth, P. Salvador, J. J. Dannenberg, V. G. Zakrzewski, S. Dapprich, A. D. Daniels, M. C. Strain, O. Farkas, D. K. Malick, A. D. Rabuck, K. Raghavachari, J. B. Foresman, J. V. Ortiz, Q. Cui, A. G. Baboul, S. Clifford, J. Cioslowski, B. B. Stefanov, G. Liu, A. Liashenko, P. Piskorz, I. Komaromi, R. L. Martin, D. J. Fox, T. Keith, M. A. Al-Laham, C. Y. Peng, A. Nanayakkara, M. Challacombe, P. M. W. Gill, B. Johnson, W. Chen, M. W. Wong, C. Gonzalez, J. A. Pople. Gaussian, Inc.: Wallingford CT, 2009.

[24] L. Drahos, K. Vékey. MassKinetics: a theoretical model of mass spectra incorporating physical processes, reaction kinetics and mathematical descriptions. J. Mass Spectrom. 2001, 36, 237.

[25] A. R. Dongré, J. L. Jones, A. Somogyi, V. H. Wysocki. Influence of Peptide Composition, Gas-Phase Basicity, and Chemical Modification on Fragmentation Efficiency: Evidence for the Mobile Proton Model. J. Am. Chem. Soc. 1996, 118, 8365.

[26] K. A. Cox, S. J. Gaskell, M. Morris, J. Whiting. Role of the site of protonation in the low-energy decompositions of gas-phase peptide ions. J. Am. Soc. Mass Spectrom. 1996, 7, 522.

[27] E. A. Kapp, F. Schutz, G. E. Reid, J. S. Eddes, R. L. Moritz, R. A. J. O'Hair, T. P. Speed, R. J. Simpson. Mining a Tandem Mass Spectrometry Database To Determine the Trends and Global Factors Influencing Peptide Fragmentation. Anal. Chem. 2003, 75, 6251.

[28] K. Vékey, A. Somogyi, V H. Wysocki. Average Activation Energies of Low-energy Fragmentation Processes of Protonated Peptides Determined by a New Approach. Rapid Commun. Mass Spectrom. 1996, $10,911$.

[29] H. Lioe, J. Laskin, G. E. Reid, R. A. J. O'Hair. Energetics and Dynamics of the Fragmentation Reactions of Protonated Peptides Containing Methionine Sulfoxide or Aspartic Acid via Energy- and TimeResolved Surface Induced Dissociation.J. Phys. Chem. A 2007, 111, 10580.

[30] B. J. Bythell, S. Suhai, A. Somogyi, B. Paizs. Proton-Driven Amide Bond-Cleavage Pathways of Gas-Phase Peptide lons Lacking Mobile Protons. J. Am. Chem. Soc. 2009, 131, 14057.

[31] J. Laskin, J. H. Futrell. Surface-Induced Dissociation of Peptide Ions: Kinetics and Dynamics. J. Am. Soc. Mass Spectrom. 2003, 14, 1340.

[32] T. H. Bailey, J. Laskin, J. H. Futrell. Energetics of selective cleavage at acidic residues studied by time- and energy-resolved surfaceinduced dissociation in FT-ICR MS. Int. J. Mass Spectrom. 2003, 222, 313.

[33] J. Laskin, T. H. Bailey, J. H. Futrell. Fragmentation energetics for angiotensin II and its analogs from time- and energy-resolved surface-induced dissociation studies. Int. J. Mass Spectrom. 2004, 234, 89.

[34] M. Aguiar, W. Haas, S. A. Beausoleil, J. Rush, S. P. Gygi. Gas-Phase Rearrangements Do Not Affect Site Localization Reliability in Phosphoproteomics Data Sets. J. Proteome Res. 2010, 9, 3103.

[35] N. Mischerikow, A. F. Maarten Altelaar, J. Daniel Navarro, S. Mohammed, A. J. R. Heck. Comparative Assessment of Site Assignments in CID and Electron Transfer Dissociation Spectra of Phosphopeptides Discloses Limited Relocation of Phosphate Groups. Mol. Cell. Proteomics 2010, 9, 2140. 